\title{
INFANT FEEDING PRACTICES AND ANALYSIS OF FACTORS AFFECTING EXCLUSIVE BREASTFEEDING
}

\section{Wenny Artanty Nisman*1, Dea Aryas², Evi Ratnasari², Melinda Widya², Nevira Yonanta², Salma Rahmasari², Varianti Novia Annisa²}

1. Pediatric and Maternity Nursing Department, Faculty of Medicine, UGM, Yogyakarta, Indonesia

2. School of Nursing, Faculty of Medicine, UGM, Yogyakarta, Indonesia

\section{Article Information}

Received: 17 July 2021

Revised: 27 October 2021

Accepted: 18 November 2021

\section{*Corresponding Author}

Wenny Artanty Nisman

Wenny.artanty@ugm.ac.id

\section{DOI}

10.20884/1.jks.2021.16.3.1726

\begin{abstract}
The coverage rate of exclusive breastfeeding in Indonesia is still low despite its ability to affect a baby's health status and ability to survive. In 2017 , only $35.73 \%$ of babies in Indonesia received exclusive breastfeeding for up to 6 months. This study aims to determine infant feeding practices and identify the factors that influence the practice of exclusive breastfeeding in Yogyakarta. This is a descriptive analysis study with a cross-sectional approach. The instruments that have been used in this study were the demographic data questionnaire, the lowa Infant Feeding Attitude Scale (IIFAS) questionnaire, and the Breastfeeding Self Efficacy Scale-Short Form (BSES-SF) questionnaire. A total of 421 mothers were involved in this study and the research was conducted between June 2019 to April 2020 in Sleman Regency, Yogyakarta, Indonesia. Correlation data analysis was performed using chi-square and point biserial correlation and the multivariate analysis used logistic regression. Infant feeding practice was high with $82.4 \%$ of infants receiving exclusive breastfeeding. It was found that employment status, knowledge, mothers' attitudes, and self-efficacy about breastfeeding have significant correlations with exclusive breastfeeding. Employment status, knowledge, mothers' attitudes, and self-efficacy about breastfeeding are factors that can encourage exclusive breastfeeding.
\end{abstract}

Keywords: Breastfeeding; breastfeeding attitudes; exclusive breastfeeding; infant feeding practices; self-efficacy of breastfeeding

\section{INTRODUCTION}

The infant mortality rates in Yogyakarta Province were high and fluctuated between 2014 to 2017 . Infant mortality rates between 2014 to 2017 were 405, 329, 278, and 313 deaths per 1,000 live births, consecutively. The highest number of infant deaths was in Bantul Regency (108 cases) and the lowest was in Yogyakarta City (33 cases) (Yogyakarta Provincial Health Office, 2017). A baby's health status, growth, and development can be influenced by the breastmilk feeding pattern provided to the baby at the beginning of life. Breastmilk is very useful for boosting the baby's immune system, reduces the risk of obesity, and optimizes brain development. Therefore, children who are breastfed tend to become smarter than children who were not breastfed (Indonesia Ministry of Health, 2016).
The coverage rate of breastfeeding in Indonesia is still low. In 2017 , the number of babies who were breastfed for $0-5$ months was $46.74 \%$, while babies who were exclusively breastfed for up to 6 months were $35.73 \%$. The low coverage of breastfeeding is also seen in almost all regions in Indonesia. The province in Indonesia that have the best coverage of breastfeeding is the Yogyakarta area, where the number of babies who are breastfed for 0-5 months was $66.12 \%$, while the number of babies who are breastfed for up to 6 months or exclusively breastfed was $61.45 \%$ (Indonesia Ministry of Health, 2018). The highest percentage of exclusive breastfeeding occurred in Sleman Regency and the lowest occurred in Yogyakarta City (Yogyakarta Provincial Health Office, 2017). 
According to the Indonesian government regulation number 33 of 2012, health workers and health service providers are required to provide information and education about exclusive breastfeeding to mothers or baby's family members from pregnancy until the end of the exclusive breastfeeding period.

However, providing the best breastfeeding practices with exclusive breastfeeding is not easy and extra effort from the mother is needed. Mothers' knowledge about infant feeding in the community still varies, therefore to make it easier to categorize, the World Health Organization (WHO) defines infant feeding practices as follows: 1) exclusive breastfeeding means babies are only given breast milk, but it can still be called exclusive breastfeeding if the babies are in special conditions and must be administered oral rehydration solution (ORS), and drops or syrups (vitamins, minerals, medicines), 2) predominant breastfeeding is when babies are given breast milk along with other liquid nutritional sources such as water, water-based drinks, fruit juices, ORS, and drops or syrups (vitamins, minerals, medicines), 3) breastfeeding with complementary foods is when babies are given breast milk and are accompanied by solid and semi-solid foods or liquids which include formula milk, and 4) breastfeeding is when babies are given breast milk with food or fluids including formula milk (WHO, 2007).

There are several factors that can affect the implementation of exclusive breastfeeding, including: knowledge about exclusive breastfeeding, children's age, and mother's education level (Mogre et al., 2016). Other factors are access to information, family support, parity and type of delivery, previous breastfeeding experience, and mother's employment status (Ketbi et al., 2018 and Mensah et al., 2017). Based on these data, the researchers of this study were interested in determining the practice of infant feeding and identifying the factors that influence the practice of exclusive breastfeeding in the Yogyakarta area of Indonesia.

\section{METHOD}

This is a descriptive analytical study with a cross-sectional approach and was conducted from June 2019 to April 2020. This study was conducted in Sleman Regency because this regency has the highest breastfeeding coverage in Yogyakarta Province. The research used cluster random sampling to select 10 public health centers (puskesmas) out of 25 health centers in Sleman Regency for this study.

Based on data DIY Province Health profile 2017, the number of babies in Yogyakarta Province was 28,208 babies, and the number of babies in Sleman Regency was 8,420 babies. By extrapolation, this data can provide an estimate of the number of babies in Sleman Regency in 2019. Based on the Slovin formula, the minimum number of samples needed for this study was 401 samples. The number of samples that was used in this study was 421 samples. Data collection was done in each puskesmas when the infant immunization service was taking place. Research subjects were selected based on our inclusion and exclusion criteria. This research's inclusion criteria were mothers who have babies aged less than 7 months, are willing to be research respondents, and can read, write, and communicate well. The exclusion criteria for this study were mothers who had mental disorders and mothers who did not live with their babies and did not breastfeed their babies.

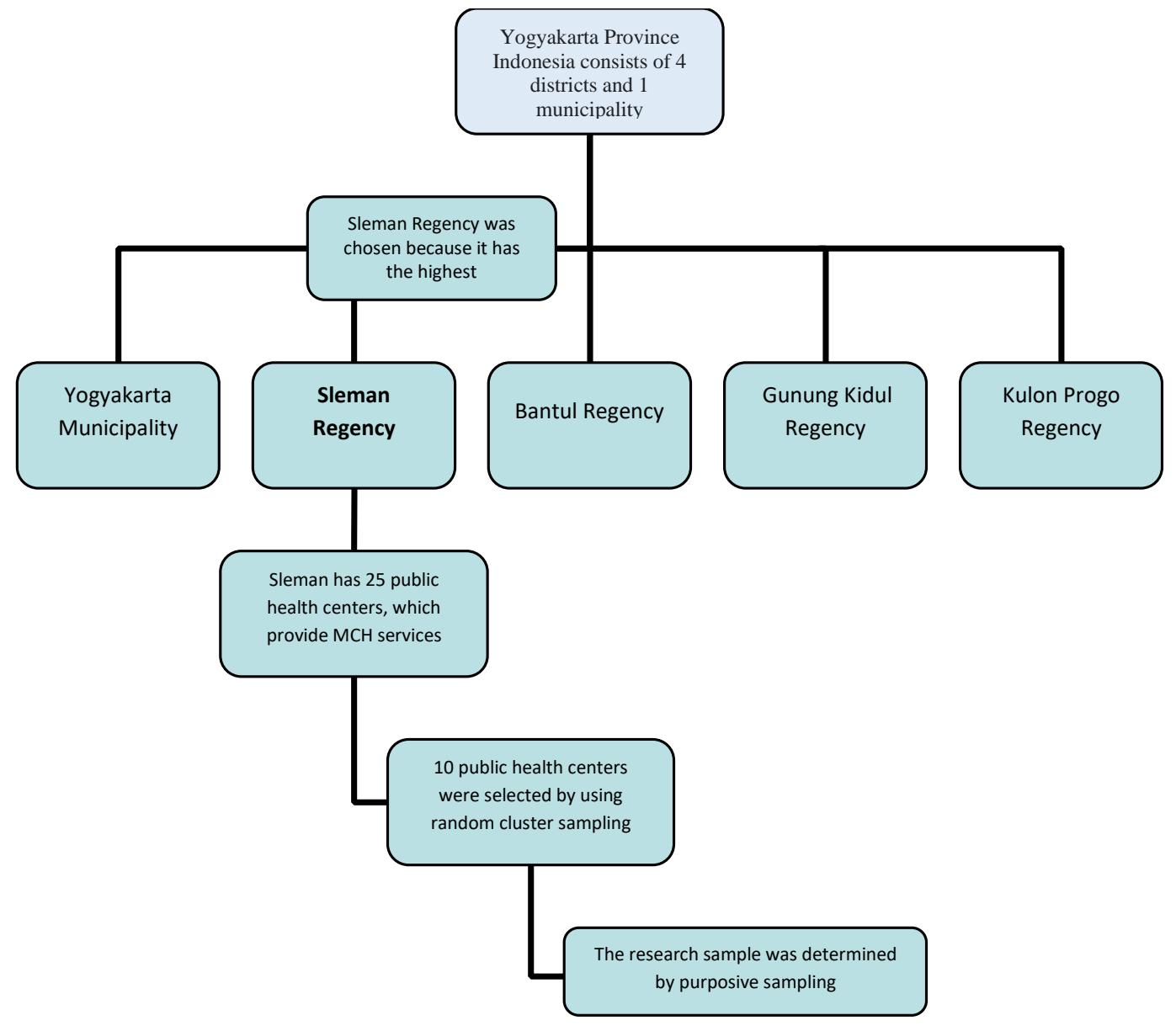

Figure 1. Sampling Technique 
The instruments that have been used in this study were the demographic data questionnaire, the lowa Infant Feeding Attitude Scale (IIFAS) questionnaire, and the Breastfeeding Self Efficacy Scale-Short Form (BSES-SF) questionnaire. This questionnaire has been translated and back translated, and it has also been declared valid and reliable. The mothers filled the questionnaire with the help of a research assistant because most of the mothers came to the puskesmas with their babies. Univariate analysis was done using percentage, mean, median, standard deviation (SD), and minimum maximum data, while analysis of the relationships between variables was conducted using chi-square and point biserial correlation tests with multivariate logistic regression analysis.

\section{RESULTS}

Table 1 shows the characteristics of the respondents, with most of the respondents being in the age range of 20-35 years. Most of the babies are less than 6 months old, while most of the mothers have low and middle education and are not working outside the home (housewife). The household income of some respondents is greater than the regional minimum wage in Sleman Regency. For parity, more than half of the respondents are multiparous with the previous number of children being mostly one child. The type of delivery for most mothers (64.3\%) was normal birth and some gave birth by cesarean delivery. The majority of the respondents also had previous breastfeeding experience and $84.8 \%$ had received health education about breastfeeding. Almost all respondents received social support from their husbands or families regarding breastfeeding. Most of the respondents received information about breastfeeding from health workers and health cadres, while others received information from friends, family members, as well as mass and electronic media.

Table 1. Respondents' Characteristics $(n=421)$

\begin{tabular}{|c|c|c|}
\hline Characteristics of respondents & $\mathbf{n}$ & $\%$ \\
\hline \multicolumn{3}{|l|}{ Mother's age (years) } \\
\hline Health reproduction (20-35) & 341 & 81.0 \\
\hline Young reproduction $(<20)$ dan old $(>35)$ & 80 & 19.0 \\
\hline \multicolumn{3}{|l|}{ Infant's age } \\
\hline$<6$ month & 368 & 87.4 \\
\hline$\geq 6$ month & 53 & 12.6 \\
\hline \multicolumn{3}{|l|}{ Mother's last education } \\
\hline Low and secondary education & 403 & 95.7 \\
\hline Higher education & 18 & 4.3 \\
\hline \multicolumn{3}{|l|}{ Employment status } \\
\hline Work & 120 & 28,5 \\
\hline Does not work (housewife) & 301 & 71,5 \\
\hline \multicolumn{3}{|l|}{ Household income } \\
\hline$\geq$ Regional Minimum Wage Sleman & 283 & 67.2 \\
\hline$<$ Regional Minimum Wage Sleman & 138 & 32.9 \\
\hline \multicolumn{3}{|l|}{ Parity } \\
\hline Primipara & 178 & 42.3 \\
\hline Multipara & 243 & 57.7 \\
\hline \multicolumn{3}{|l|}{ The number of children before } \\
\hline 1 child & 343 & 81.5 \\
\hline 2 children & 78 & 18.5 \\
\hline \multicolumn{3}{|l|}{ Type of delivery } \\
\hline Normal & 270 & 64.1 \\
\hline Sectio Caesarea & 151 & 35.9 \\
\hline \multicolumn{3}{|l|}{ Previous breastfeeding experience } \\
\hline Ever & 244 & 58.0 \\
\hline Never & 177 & 42.0 \\
\hline \multicolumn{3}{|l|}{ Experience getting information about breastfeeding } \\
\hline Ever & 357 & 84.8 \\
\hline Never & 64 & 15.2 \\
\hline \multicolumn{3}{|l|}{ Social support } \\
\hline Yes & 399 & 94.8 \\
\hline No & 22 & 5.2 \\
\hline \multicolumn{3}{|l|}{ Sources of information about breastfeeding } \\
\hline Family (husband, parent) & 75 & 12.5 \\
\hline Health workers & 288 & 47.9 \\
\hline Health cadres & 104 & 17.3 \\
\hline Friends & 39 & 6.5 \\
\hline $\begin{array}{l}\text { Media (TV, radio, magazine, internet, advertisements, movie, books, leaflets, } \\
\text { newspapers, etc.) }\end{array}$ & 95 & 15.8 \\
\hline
\end{tabular}


Table 2. Infant Feeding Practices ( $\mathrm{n}=421)$

\begin{tabular}{|c|c|c|}
\hline Infant feeding practices & $\mathbf{n}$ & $\%$ \\
\hline \multicolumn{3}{|l|}{ Breastfeeding status $(n=421)$} \\
\hline Exclusive & 347 & 82.4 \\
\hline Not exclusive & 74 & 17.6 \\
\hline \multicolumn{3}{|l|}{ For all babies $(n=421)$} \\
\hline Exclusive breastfeeding & 347 & 82.4 \\
\hline Predominant breastfeeding & 63 & 15.0 \\
\hline Complementary breastfeeding & 11 & 2.6 \\
\hline \multicolumn{3}{|c|}{ For babies less than 6 months $(n=368)$} \\
\hline Exclusive breastfeeding & 303 & 82.3 \\
\hline Predominant breastfeeding & 57 & 15.5 \\
\hline Complementary breastfeeding & 8 & 2.2 \\
\hline \multicolumn{3}{|c|}{ For babies more than 6 months $(n=53)$} \\
\hline Exclusive breastfeeding & 44 & 83 \\
\hline Predominant breastfeeding & 6 & 11 \\
\hline Complementary breastfeeding & 3 & 5 \\
\hline
\end{tabular}

Based on data from Table 2 about infant feeding practices, the breastfeeding status showed that most babies $(82.4 \%)$ received exclusive breastfeeding, while some babies (17.6\%) did not receive exclusive breastfeeding, $15 \%$ received predominant breastfeeding, and $2.6 \%$ received complementary breastfeeding. If the feeding practices were divided into age ranges of less than 6 months and more than 6 months, above $80 \%$ of infants were exclusively breastfed in both groups.

Table 3. Correlation of Factors Influencing Infant Feeding Practices $(n=421)$

\begin{tabular}{|c|c|c|c|c|c|c|}
\hline \multirow[t]{2}{*}{ Characteristic respondents } & \multicolumn{2}{|c|}{ Breastfeeding status } & \multirow{2}{*}{$\begin{array}{c}\text { Total } \\
(n=421)\end{array}$} & \multirow[t]{2}{*}{$P$ value } & \multirow[t]{2}{*}{ OR } & \multirow[t]{2}{*}{$95 \% \mathrm{Cl}$} \\
\hline & $\begin{array}{c}\text { Exclusive } \\
\text { breastfeeding } \\
(n=347) \\
n(\%)\end{array}$ & $\begin{array}{c}\text { Not exclusive } \\
\text { breastfeeding } \\
(n=74) \\
n(\%)\end{array}$ & & & & \\
\hline Mother's last education & & & & 1.000 & 0.935 & $0.264-3.316$ \\
\hline Low and secondary education & 245 (81.9) & $54(18.1)$ & 299 & & & \\
\hline Higher education & $101(83.4)$ & $20(16.6)$ & 121 & & & \\
\hline Mother's Age (years) & & & & 0,426 & 1.344 & $0.733-2.466$ \\
\hline Health reproduction (20-35) & $284(83.3)$ & $57(16.7)$ & 341 & & & \\
\hline $\begin{array}{l}\text { Young }(<20) \text { and old }(>35) \\
\text { reproduction }\end{array}$ & $63(78.8)$ & $17(21.2)$ & 80 & & & \\
\hline Infant's age & & & & 1.000 & 0.953 & $0.443-2.050$ \\
\hline$<6$ month & 303(82.3) & $65(17.7)$ & 368 & & & \\
\hline$\geq 6$ month & $44(83.0)$ & $9(17.0)$ & 53 & & & \\
\hline Employment status & & & & 0,008 & 0.478 & $0.284-0.806$ \\
\hline Work & $89(74.2)$ & $31(25.8)$ & 120 & & & \\
\hline Does not work (housewife) & $258(85.7)$ & $43(14.3)$ & 301 & & & \\
\hline Household income & & & & 1.000 & 0.981 & $0.574-1.676$ \\
\hline $\begin{array}{l}\geq \text { Regional Minimum Wage } \\
\text { Sleman }\end{array}$ & $233(82.3)$ & $50(17.7)$ & 283 & & & \\
\hline $\begin{array}{l}<\text { Regional Minimum Wage } \\
\text { Sleman }\end{array}$ & $114(82.6)$ & $24(17.4)$ & 138 & & & \\
\hline Type of delivery & & & & 0.991 & 0.962 & $0.569-1.627$ \\
\hline Normal & $222(82.2)$ & $48(17.8)$ & 270 & & & \\
\hline Sectio Caesarea & $125(82.8)$ & $26(17.2)$ & 151 & & & \\
\hline The number of children before & & & & 0.945 & 0.925 & $0.479-1.783$ \\
\hline 1 child & 282(82.2) & $61(17.8)$ & 343 & & & \\
\hline 2 children & $65(83.3)$ & $13(16.7)$ & 78 & & & \\
\hline Parity & & & & 0,062 & 0.600 & $0.362-0.993$ \\
\hline Primipara & $139(78.1)$ & $39(21.9)$ & 178 & & & \\
\hline Multipara & $208(85.6)$ & $35(14.4)$ & 243 & & & \\
\hline Previous breastfeeding experience & & & & 0,255 & 1.384 & $0.836-2.290$ \\
\hline Ever & $206(84.4)$ & $38(15.6)$ & 244 & & & \\
\hline Never & $141(79.7)$ & $36(20.3)$ & 177 & & & \\
\hline Experience getting information abou & ut breastfeeding & & & 0,929 & 1.098 & $0.554-2.178$ \\
\hline Ever & 295 (82.6) & $62(17.4)$ & 357 & & & \\
\hline Never & $52(81.2)$ & $12(18.8)$ & 64 & & & \\
\hline
\end{tabular}




\begin{tabular}{|c|c|c|c|c|c|c|}
\hline \multirow[t]{2}{*}{ Characteristic respondents } & \multicolumn{2}{|c|}{ Breastfeeding status } & \multirow{2}{*}{$\frac{\text { Total }}{(n=421)}$} & \multirow[t]{2}{*}{$P$ value } & \multirow[t]{2}{*}{ OR } & \multirow[t]{2}{*}{$95 \% \mathrm{Cl}$} \\
\hline & $\begin{array}{c}\text { Exclusive } \\
\text { breastfeeding } \\
(\mathrm{n}=347) \\
\mathrm{n}(\%)\end{array}$ & $\begin{array}{c}\text { Not exclusive } \\
\text { breastfeeding } \\
(\mathrm{n}=74) \\
\mathrm{n}(\%)\end{array}$ & & & & \\
\hline Social support & & & & 0.833 & 0.729 & $0.210-2.532$ \\
\hline Yes & $328(82.2)$ & $71(17.8)$ & 399 & & & \\
\hline \multirow[t]{2}{*}{ No } & $19(86.4)$ & $3(13.6)$ & 22 & & & \\
\hline & Mean (SD) & \multicolumn{2}{|c|}{ Mean (SD) } & $p$ value & rpb & \\
\hline Mother's age & $29.35(5.68)$ & \multicolumn{2}{|c|}{$29.68(6.33)$} & 0.655 & 0.022 & \\
\hline Knowledge about breastfeeding & $13.93(1.06)$ & \multicolumn{2}{|c|}{$13.66(0.94)$} & 0.045 & -0.098 & \\
\hline $\begin{array}{l}\text { Mothers' attitude about } \\
\text { exclusive breastfeeding }\end{array}$ & $60.38(4.85)$ & \multicolumn{2}{|c|}{$58.83(4.85)$} & 0.013 & -0.121 & \\
\hline Breastfeeding self-efficacy & $56.04(5.07)$ & \multicolumn{2}{|c|}{$51.89(7.21)$} & 0.000 & -0.277 & \\
\hline
\end{tabular}

Based on Table 3, employment status, maternal knowledge, maternal attitudes, and breastfeeding self-efficacy have a significant correlation with exclusive breastfeeding. While other factors such as the mother's last education level, age, infant's age, family income, type of delivery, number of previous children, parity status, breastfeeding experience, experience of getting health education, and family support, did not correlate with exclusive breastfeeding. For the multivariate analysis, bivariate test results were selected with a $p$ value of $<0.25$, from this the factors employment status, parity status, knowledge, attitudes, and self-efficacy were found. The multivariate test was conducted by selecting the enter method.

Table 4. Multivariate Analysis

\begin{tabular}{lcccc}
\hline Variable & & \multicolumn{2}{c}{ Model 1 } \\
\cline { 2 - 5 } & Coef (B) & t & p-value & SE \\
\hline (constant) & 3.204 & 8.890 & 0.000 & 0.360 \\
Parity & -0.070 & -1.938 & 0.053 & 0.036 \\
Employment status & -0.112 & -2.846 & 0.005 & 0.039 \\
Knowledge about breastfeeding & -0.029 & -1.709 & 0.088 & 0.017 \\
Mother's Attitude about exclusive breastfeeding & -0.006 & -1.701 & 0.090 & 0.004 \\
Breastfeeding self- efficacy & -0.017 & -5.322 & 0.000 & 0.003 \\
F value & 10.808 & & & \\
R square & 0.115 & & & \\
P value & 0.000 & & & \\
\hline
\end{tabular}

Based on Table 4, breastfeeding self-efficacy and employment status have a dominant influence on the implementation of exclusive breastfeeding, and together with parity, knowledge about breastfeeding, mother's attitudes about exclusive breastfeeding, and breastfeeding selfefficacy contribute to the implementation of exclusive breastfeeding by $11.5 \%$, and the remaining are influenced by other factors that were not examined in this study.

\section{DISCUSSION}

Based on the results of this study, it can be concluded that the rate of exclusive breastfeeding reached $82.4 \%$ for all babies, where the rate of exclusive breastfeeding for babies aged less than 6 months was 82.3\%, and for babies over 6 months was $83 \%$. The rate for exclusive breastfeeding has decreased when compared to the rate for exclusive breastfeeding in Yogyakarta Province in 2017, which was $87.43 \%$. The implementation rate for exclusive breastfeeding is much higher when compared to the national level of exclusively breastfed (EBF) infants in 2017, which was $61.33 \%$. The highest achievement rate in Indonesia is in the West Nusa Tenggara Province, namely, 87.35\% (Indonesia Ministry of Health, 2018).

The high EBF achievement rate is also similar to the results of a study by Morais et al. (2017) in 11 cities in Brazil, which found that $81.7 \%$ of babies were breastfed for up to 6 months. A fairly high achievement of exclusive breastfeeding in Mashhad, Iran, reached 73.8\% (Hoseini et al., 2014).
However, there are many notable places where the EBF achievement is still very low: the prevalence of EBF in the Burao District of Somalia is 20.4\% (Jama et al., 2020), 20.9\% in South Jordan (Altamimi et al., 2017), 16.9\% in Abu Dhabi, United Arab Emirates (Ketbi et al., 2018), and the EBF prevalence was only $24.1 \%$ in the Muheza District of Tanga in Northeastern Tanzania (Maonga et al., 2016). Moreover, EBF practice was $33.5 \%$ in Nnewi South-East Nigeria (Onah et al., 2014) and 34\% in Tamil Nadu (Radhakrishnan and Balamuruga, 2012).

The causes of low EBF achievement are due to low maternal nutrition, pressure from mothers to return to work after maternity leave, low knowledge of breastfeeding, perceptions of lack of breast milk produced, and conflicting advice from families and health workers (Mgongo et al., 2018). In addition, the low achievement of EBF is also caused by the mothers' perception, especially mothers who work outside the home, who believe that formula milk is better than breast milk (Wambach et al., 2016). The lack of implementation or failure of EBF is related to the formal education of mothers, low family income, lack of advice on breastfeeding since pregnancy, and lack of support from husbands (Jama et al., 2020). Mothers who have had a good level of formal education had greater access to information, including information about EBF. Low family income, lack of advice on breastfeeding since pregnancy, and lack of support from husbands are some of the factors that can hinder the achievement of exclusive breastfeeding. Therefore, extra preparation needs to be done. 
The mother's employment status influences EBF ( $p$ value 0.008 ), since mothers who do not work have a greater likelihood of being able to provide exclusive breastfeeding compared with working mothers. The results of this study are also in line with the research of Mensah et al. (2017) which found that mothers who work in the public and private sectors are less likely to achieve EBF compared to mothers who are self-employed. The reason is because mothers who are selfemployed can better manage their work schedules and breastfeeding schedules. This is also consistent with the situation in Sleman, Yogyakarta, Indonesia, where most mothers who do not work outside the home or are housewives have a more flexible time to do household chores and breastfeed their babies, making it easier to implement EBF. Conversely, the results of the research by Mundagowa et al. (2019) stated that the work status of mothers is not related to EBF, although there is a greater proportion of mothers who do not work that implement EBF.

The next factor that affects exclusive breastfeeding is maternal knowledge. The mother's knowledge is related to EBF ( $p$ value 0.045). Ketbi et al. (2018) and Mensah et al. (2017) have also found that there is a relationship between the mother's knowledge and EBF. This is also in line with the study of Susiloretni et al. (2015) which found that mothers' high knowledge about breastfeeding is related to the duration of breastfeeding.

Moreover, the role of health workers in providing health education about breastfeeding is essential. According to a study from Turkey, health workers' knowledge about breastfeeding is still low, and this has an impact on the low percentage of recommendations for EBF from health workers to breastfeeding mothers (Artantas et al., 2016). In addition, it is necessary to think about increasing the knowledge of breastfeeding mothers by providing special health education programs such as through training sessions. This has been done by previous research and showed positive results as mothers who received training about breastfeeding increased their maternal self-efficacy and are also expected to improve their EBF practice (Nursan et al., 2014).

The following factor is the attitude about EBF, as measured by the IIFAS. Based on the results of the study, the average score of attitudes about EBF in the group that can implement EBF was 60.38 , while the group that cannot implement EBF was 58.83. There was a correlation between attitude and EBF ( $p$ value 0.013 ). The same finding was also conveyed in research on positive attitudes about EBF which was also shown by most of the research respondents $(71.0 \%)$ in a study conducted by Onah et al. (2014) in Southeast Nigeria. Additionally, Altamimi et al. (2017) stated that participants who have good knowledge about breastfeeding will also have positive attitudes about breastfeeding.

The self-efficacy of breastfeeding mothers also influences EBF ( $p$ value 0.00$)$. This indicates that the higher the mothers' self-efficacy for breastfeeding and providing exclusive breastfeeding, the higher the success of exclusive breastfeeding. According to the research by Shariat et al. (2018), teaching about self-efficacy and providing information and awareness about breastfeeding and psychological interventions will have a beneficial effect on EBF and are effective in improving long-term breastfeeding practices. Nursan et al. (2014) showed that breastfeeding self-efficacy is still low in mothers who have no previous experience of breastfeeding, so they need additional support from health workers. Moreover, based on Bandura's theory of social learning theory, self-efficacy is an individual's cognitive process that can predict health behavior. By applying the selfefficacy theory as a framework for maternal trust, research showed that self-efficacy expectations can influence women's judgment about their ability to initiate, survive, and continue breastfeeding (Dennis, 1999).

The variables of previous breastfeeding experience and the experience of obtaining health education about breastfeeding were not related to EBF because both variables did not reflect the mothers' intention to breastfeed and did not have an impact on the length of the breastfeeding process (Susiloretni et al., 2015).

The parity status in this study differs from the results of previous studies which stated that EBF implementation is higher for multiparous women than that of primiparous women. The experience of having previous children can become a lesson for women to implement exclusive breastfeeding. The same opinion was also conveyed by a study conducted by lhudiebube-Splendor (2019) which stated that primiparous mothers have low knowledge and intentions for EBF. In this study, $57.8 \%$ of primiparous women have inadequate knowledge of EBF and only $62.7 \%$ of primiparous women have the intention to provide exclusive breastfeeding. The multivariate analysis results showed that mothers' employment status and self-efficacy have a partial effect on the implementation of exclusive breastfeeding, and together with the factors of parity, knowledge, attitude, and selfefficacy, contribute to the achievement of exclusive breastfeeding by $11.5 \%$. The remainder was influenced by other factors that were not identified in this study.

When breastfeeding mothers have returned to work, it will be more difficult to exclusively breastfeed because mothers cannot always be with their babies. High maternal selfefficacy is needed to achieve this. Additional efforts that need to be made by working mothers are expressing breast milk, storing breast milk, and giving breast milk to their infants with certain techniques when they go to work. Moreover, breastfeeding must be supported by another family member or babysitter. This may affect the implementation of exclusive breastfeeding and has not been investigated in this study.

\section{CONCLUSION AND RECOMMENDATION}

Infant feeding practice for all infants aged 1-6 months was $82.4 \%$, for infants less than 6 months it was $82.3 \%$, and for infants more than 6 months, $83 \%$ of the respondents' infants were exclusively breastfed. Employment status, knowledge, mothers' attitudes, and self-efficacy about breastfeeding have a significant correlation with exclusive breastfeeding, while other factors did not have a correlation with the implementation of exclusive breastfeeding. Mother's employment status and breastfeeding self-efficacy are the dominant factors that influence the implementation of exclusive breastfeeding, along with other factors such as parity, knowledge, and attitudes, which contribute to the implementation of exclusive breastfeeding by $11.5 \%$, while the remainder are influenced by other factors that were not examined in this study.

\section{ACKNOWLEDGMENT}

This research was supported by a research grant from the Faculty of Medicine, Universitas Gadjah Mada. 


\section{REFERENCES}

Altamimi, E., Al Nsour, R., Al dalaen, D., and Almajali N. (2017) Knowledge, attitude, and practice of breastfeeding among working mothers in South Jordan, Workplace Health \& Safety: 65(5) p 210-218 DOI: $10.1177 / 2165079916665395$ http://www.sage pub.com/ journalsPermissions.nav

Artantas, A. B. Tetik, B. K, Kılıc. M., Eray, I. K., Cetin, N., Güney, S., Akdogan, D., Domac, U., Ustu, Y., Ugurlu, E., (2016). Knowledge level, attitude and own experience of health professionals about breastfeeding and breast milk in a city of Turkey: cross-sectional study, Arch Argent Pediatr:114(6): 514-520

Dennis, C. L., (1999), Theorical underpinning of breastfeeding confidence: a self-efficacy framework, Journal of Human Lactation 15(3), complementary, 195-291.

Hoseini, B. L., Vakili, R, Kiani, M. A., Khakshour, A., Saeidi, M., (2014). Maternal knowledge and attitude toward exclusive Breast Milk Feeding (BMF) in the first 6 months of infants in Mashhad, Iran. International Journal of Pediatrics, 2(1),p 63-69

Ihudiebube-Splendor, C.N., Okafor, C. B., Anarado, A. N., Jisieike-Onuigbo, N. N., Chinweuba, A. U., Nwaneri, A. C., Arinze, J. C., Chikeme, P. C., (2019). Exclusive breastfeeding knowledge, intention to practice and predictors among primiparous women in Enugu South-East, Nigeria, Hindawi Journal of Pregnancy Volume 2019, Article ID 9832075, pages 1-8, https://doi.org/10.1155/2019/9832075.

Jama, A., Gebreyesus, H., Wubayehu,T., Gebregyorgis, T., Teweldemedhin, M., Berhe, T., and Berhe, N., (2020) Exclusive breastfeeding for the first six months of life and its associated factors among children age 6-24 months in Burao district, Somaliland, International Breastfeeding Journal 15(5) p 3-8 https://doi.org/10. 1186/s13006-020-0252-7

Indonesian Ministry of Health (2016), Here are the Ten Benefits of Breastfeeding, www.kemkes.go.id, Publication date 01 OCT 2016

Indonesia Ministry of Health (2018) Data and information on Indonesia's health profile in 2017

Indonesian Ministry of Health, (2018), Indonesia Health Profile 2017, Ministry of Health RI. Secretariat General, Jakarta, Indonesia

Ketbi, M. I., Noman,S., Ali, A., Darwish, E., Fahim, M., and Rajah. J., (2018) Knowledge, attitudes, and practices of breastfeeding among women visiting primary healthcare clinics on the island of Abu Dhabi, United Arab Emirates, Al Ketbi et al. International Breastfeeding Journal 13(26),p1-14 https://doi.org/ 10.1186/s13006-018-0165-x

Maonga, A. R., Mahande, M. J., Damian, D. J., Msuya, S. E., (2016). Factors affecting exclusive breastfeeding among women in Muheza District Tanga Northeastern Tanzania: a mixed method community based study, Maternal Child Health Journal 20:77-87 DOI 10.1007/s10995-015-1805-z

Mensah, K. A., Acheampong. E., Anokye, F. O., Okyere, P., Appiah-Brempong, E., and Adjei, R. O., (2017) Factors influencing the practice of exclusive breastfeeding among nursing mothers in a peri-urban district of Ghana, Mensah et al. BMC Res Notes 10:466 DOI 10.1186/s13104-017-2774-7

Mgongo. M., Hussein, T. H., Pedersen, B. S., Vangen, S., Msuy, S. E., and Wandel, M., (2018) "We give water or porridge, but we don't really know what the child wants:" a qualitative study on women's perceptions and practises regarding exclusive breastfeeding in Kilimanjaro region, Tanzania, BMC Pregnancy and Childbirth (2018) 18:323, https://doi.org/10.1186/s12 884-018-1962-3

Mogre, V., Dery, M., \& Gaa, P. K. (2016). Knowledge, attitudes and determinants of exclusive breastfeeding practice among Ghanaian rural lactating mothers, International Breastfeeding Journal 11(12)p 1-8. https://doi.org/10.1186/s13006-016-0071-z

Morais, M. B., Cardoso, A. L., Lazarini, T., Mosquera, E. M. B., Mallozi, M. C., (2017) Habits and attitudes of mothers of infants in relation to breastfeeding and artificial feeding in 11 brazilian cities, Rev Paul Pediatr ;35(1):39-45, http://dx.doi.org/10.1590/1984-0462/; 2017;35;1;00014

Mundagowa., Chadambuka., Chimberengwa., MukoraMutseyekwa., (2019) Determinants of exclusive breastfeeding, Determinant of exclusive breastfeeding among mother of infants aged 6 to 12 moth in Gwanda District, Zimbabwe. International Breastfeeding Journal 14:30 https://doi.org/10.1186/s13006-019-02 $25-x$

Nursan, C., Dilek, K., Sevin, A., (2014) Breastfeeding Selfefficacy of Mothers and the Affecting Factors. Aquichan; 14(3): 327-335. DOI: 10.5294/aqui.2014. 14.3.5,

Onah S., Osuorah D I C., Ebenebe J., Ezechukwu C., Ekwochi U., Ndukwu I., (2014) Infant feeding practices and maternal socio-demographic factors that influence practice of exclusive breastfeeding among mothers in Nnewi South-East Nigeria: a crosssectional and analytical study, International Breastfeeding Journal; 9:(6): p1-10, http://www. internationalbreastfeedingjournal.com/content/9/1/6

Radhakrishnan S., Balamuruga S. S., (2012) Prevalence of exclusive breastfeeding practices among rural women in Tamil Nadu, International Journal of Health \& Allied Sciences 1(2):64: p 63-67 DOI: 10.4103/2278344X.101667, [Downloaded free from http://www.ijhas.in on Wednesday, February 13, 2019, IP: 202.43.93.18]

Shariat M., Abedinia N., Noorbala A. A., Zebardas. J., Moradi .S., Shahmohammadian. N., Karimi. A., Abbasi. M., (2018). Breastfeeding Self-Efficacy as a Predictor of Exclusive Breastfeeding: A Clinical Trial, Iranian, Journal of Neonatology 9(3): p 26-34. DOI: 10.22038/ijn.2018.24694.1316

Susiloretni. K.A., Hadi. H, Prabandari. Y. S., Soenarto Y. S., Wilopo. S. A., What Works to Improve Duration of Exclusive Breastfeeding: Lessons from the Exclusive Breastfeeding Promotion Program in Rural Indonesia, Maternal Child Health Journal (2015) 19: p15151525, DOI 10.1007/s10995-014-1656-z

WHO (2007) Indicators for assessing infant and young child feeding practices Part 1 definitions: conclusions of a consensus meeting held 6-8 November 2007 in Washington D.C., USA. ISBN 9789241596664 
Wambach. K., Domian. E.W., Goertz. S.P., Wurtz. H., Hoffman. K. (2016), Exclusive Breastfeeding Experiences among Mexican American Women, Journal Human Lactation. February ; 32(1):103-111. doi:10.1177/0890334415599400.
Yogyakarta Provincial Health Office, (2017) Yogyakarta Provincial Health Profile 2017 